\title{
Q-FACTOR VERIFICATION OF A 6-STOREY CONCENTRICALLY BRACED FRAME VIA THE INNOSEIS RISK-BASED APPROACH
}

\author{
Dimitrios Vamvatsikos ${ }^{1}$, Konstantinos Bakalis ${ }^{2}$, Stella Pyrza ${ }^{3}$ \\ ${ }^{1}$ National Technical University of Athens \\ Institute of Steel Structures \\ Zografou Campus, 9 Iroon Polytechneiou str, 15780 Zografou, Athens, Greece \\ e-mail: divamva@mail.ntua.gr \\ ${ }^{2}$ National Technical University of Athens \\ Institute of Steel Structures \\ Zografou Campus, 9 Iroon Polytechneiou str, 15780 Zografou, Athens, Greece \\ e-mail: kbakalis@mail.ntua.gr \\ ${ }^{3}$ National Technical University of Athens \\ Institute of Steel Structures \\ Zografou Campus, 9 Iroon Polytechneiou str, 15780 Zografou, Athens, Greece \\ e-mail: pirzast@hotmail.com
}

Keywords: Instructions, ECCOMAS Thematic Conference, Structural Dynamics, Earthquake Engineering, Proceedings.

\begin{abstract}
A case study example is presented to support a methodology that evaluates the design behaviour-factor on a risk-basis, using the code-compatible performance targets for life safety and global collapse. The case study employs a 6-storey concentrically braced frame with a detailed physics-based representation of braces. Nonlinear static analysis is conducted to provide an estimate of overstrength and an approximation of the behaviour-factor. Incremental Dynamic Analysis is subsequently performed to obtain a refined representation of response throughout the desired range of seismic intensity. Besides the widely-adopted first-mode spectral acceleration, state-of-the-art intensity measures such as the so-called average spectral acceleration, are used to illustrate the severity of the ground motions considered. The dynamic analysis results for the considered modes of failure are conveniently summarised in to fragility functions, which are further convoluted with the seismic hazard function in order to derive the associated mean annual frequency of exceedance. A comparison among the derived and the allowable mean annual frequencies determines the applicability of the behaviour factor for the structure examined, showing that EN1998-compatible factors may accurately be evaluated.
\end{abstract}




\section{INTRODUCTION}

The q-factor is a convention adopted by the earthquake engineering community to allow the elastic design of essentially inelastic structures. Its use is based on the idea that yielding and subsequent plastification reduce the strength demand on the structure at the expense of requiring increased ductility capacity and thus imposing damage. Rather than determining the ductility capacity of a given structural system, engineers are accustomed to using an "equivalent" behaviour q-factor. This factor is a single value, larger than 1.0, that is independent of period or height and is used to determine the required yield strength of the system by directly dividing the strength required for the system to remain elastic. EN 1998-1 [1] provides values of the qfactor only for a very limited number of systems without any guidance on quantifying it for others. In fact, such q-values may have been proposed by researchers for each innovative system, yet without much consensus: Each proposal comes with its own definition of safety target and seismic performance assessment method, lending little confidence to the ensemble results. Unlike the US, where the FEMA P-695 [2] standard has settled this debate, Europe has not formulated a standard methodology (barring an ECCS recommendation based on nonlinear static methods) to define and validate the q-factors. For novel structural systems, behaviour factors cannot rely on observations of their performance during past earthquakes. Along these lines, this study aims to showcase a step-by-step procedure to reliably define q-factors in order to achieve uniform safety margins against collapse, for the case of a 6-storey concentrically braced frame (CBF). The methodology is based on static pushover and dynamic response history nonlinear analyses of the building structure, using known predefined non-linear response characteristics of structural elements.

\section{RECOMMENDED PROCEDURE FOR THE DEFINITION OF Q-FACTORS}

The recently-proposed state-of-the-art procedure for obtaining consistent q-factor values [3] is based on (a) defining a class of archetype buildings, (b) employing nonlinear dynamic analysis with appropriate ground motions and intensity measures $(I M S)$, (c) fully incorporating the effect of aleatory and epistemic uncertainty on the systems' performance, (d) offering uniform safety across the entire population of buildings. The proposed methodology builds and improves upon existing literature to offer a concise approach for q-factor quantification on a probabilistic basis. In brief, structural models of the system under consideration are initially analysed via nonlinear (static) pushover analysis to determine preliminary q-factor values. Then, a set of 3-7 (or more) index buildings is statistically selected to best capture the characteristics of the envisioned population of structures. Pre-normative level assessment requires capturing only the salient characteristics of application with only 2-5 buildings, spanning the parameter space in terms of, e.g., number of stories and ductility class. Normative-level assessment requires more careful discretisation of the building population by considering, for example foundation flexibility, accidental eccentricities, vertical irregularities etc. Accurate nonlinear models are formed, where both simulated and non-simulated (non-modelled) modes of failure are determined. Incremental Dynamic Analysis [4] is then employed, using an appropriate set of records for European sites, together with a novel intensity measure $[5,6]$ that is designed to retain sufficiency across an entire class.

The target is to comply with a maximum allowable annual probability of exceeding the collapse limit-state, adjusting the q-factor and the subsequent structural designs, until convergence is achieved. Local spectral shape and hazard curve shape effects are incorporated as needed. Compatibility with the new generation of risk-targeted design spectra, currently adopted in USA and being discussed in Europe, is also addressed thus offering a common basis for avoid- 
ing any potential double-counting of uncertainties or spectral effects when combining the seismological and the structural viewpoint. The proposed q-factor estimation methodology is based on the explicit performance assessment of a number of archetype structures using two performance targets defined on a mean annual frequency of exceedance basis. It comprises seven discrete steps, taking the engineer from the site hazard to the final risk-based determination of compliance with the safety standards.

\section{VERIFICATION EXAMPLE}

\section{Step 1: Site hazard}

For the purpose of the INNOSEIS project two different sets of 3-5 sites are considered across Europe. The first set comprises moderate seismicity sites with a peak ground acceleration (or zone factor per EN1998) of approximately $a_{g}=0.15 \mathrm{~g}$, mainly geared towards evaluating behaviour factors for Ductility Class Medium (DCM) designs, whereas the second set uses highseismicity sites with $a_{g}=0.30 \mathrm{~g}$ that can be used to test Ductility Class High (DCH) buildings. Site selection is performed according to the EU-SHARE seismicity model [7]. For each set of sites, a single suite of ordinary (non-pulsive, not long duration) records is selected considering all sites within the set and employing Conditional Spectrum selection [8,9] based on the average spectral acceleration $(\operatorname{AvgSa},[6,10,11])$, i.e., the geometric mean of 5\% damped spectral acceleration ordinates $T_{R i}$ characterising the archetype buildings of interest:

$$
\operatorname{AvgSa}\left(T_{R i}\right)=\left(\prod_{i=1}^{n} S_{a}\left(T_{R i}\right)\right)^{1 / n}
$$

Periods $T_{R i}$ can be selected as linearly spaced within a range of $\left[T_{L}, T_{H}\right]$, where $T_{L}$ is a low period near the minimum second mode of the buildings to be investigated and $T_{H}$ is a high period that is near 1.5 times their maximum first mode period. If considerable difference exists among the different first mode periods, one should consider using two different definitions of $A v g S a$, one for low/mid-rise structures (shorter periods) and another for high-rise ones (longer periods), for better fidelity. In any case, ground motion records need to be selected for each definition of $A v g S a$ at a given set of sites [12,13], while mean hazard curves are required for each definition of $A v g S a$ and at each separate site.

\section{Step 2: Archetype buildings}

In order to support the methodology outlined above, a 6-storey steel building is employed. The structure considered has a storey-height equal to $3.5 \mathrm{~m}$, a bay-length of $9.0 \mathrm{~m}$, and covers a planview area of $36 \times 54 \mathrm{~m}^{2}$ as shown in Figure 1 . The lateral load-resisting system consists of concentrically X-braced frames (X-CBFs), where each brace extends between two consecutive floors. Composite beams are considered to support the concrete slab on each level, whereby connection with the pin-supported columns is established through bolted (shear) connections. The gravity loads considered regarding the top as well as the intermediate floors are summarised in Table 1. The seismic design has been performed using the response spectrum analysis in ETABS, following the Eurocode 8 [1] provisions for ductility class high (DCH) and a peak ground acceleration $(P G A) a_{g}=0.24 \mathrm{~g}$. A behaviour factor $q=4$ is adopted, and the soil properties on site are assumed to match the Eurocode 8 class B soil type, thus implying a soil amplification factor $S=1.2$ (Figure 2). The steel grade that has been used is $\mathrm{S} 355$. 


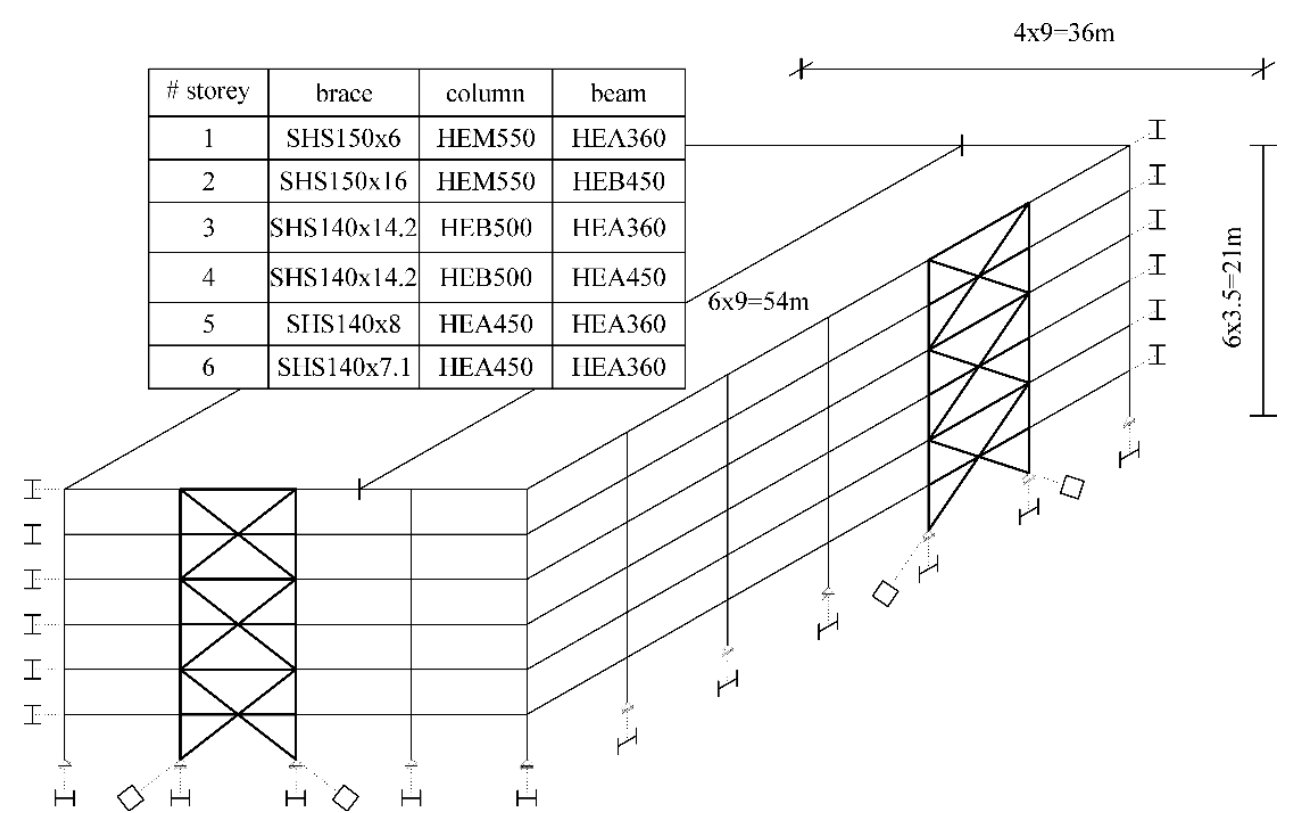

Figure 1:Case study design-basis CBFs and member cross sections on the X-brace bays

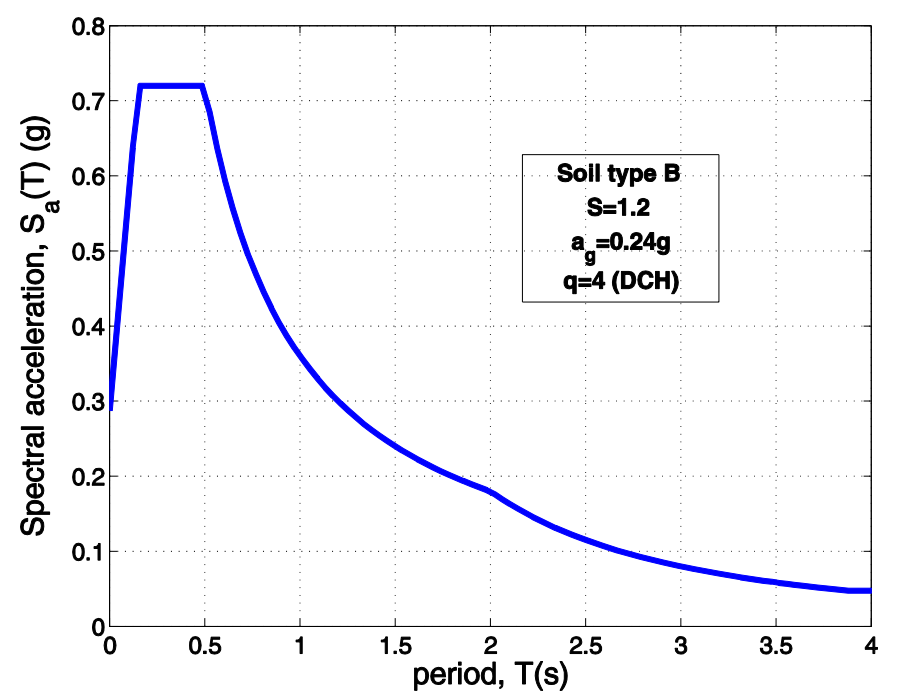

Figure 2: Elastic design spectrum

Table 1: Gravity loads considered

\begin{tabular}{c|cc}
\hline & $\mathrm{i}^{\text {th }}$ storey & Rooftop \\
\hline Concrete slab & $3.11 \mathrm{kN} / \mathrm{m}^{2}$ & $3.11 \mathrm{kN} / \mathrm{m}^{2}$ \\
Additional dead loads & $1.8 \mathrm{kN} / \mathrm{m}^{2}$ & $0.9 \mathrm{kN} / \mathrm{m}^{2}$ \\
Live loads & $2 \mathrm{kN} / \mathrm{m}^{2}$ & $2 \mathrm{kN} / \mathrm{m}^{2}$
\end{tabular}

Besides the damage-limitation and the P- $\Delta$-effect checks on a global response level, of particular interest regarding the seismic design of CBFs are the buckling braces. They should be designed such that brace-yielding appears prior to connection failure, beam yielding or column buckling. For CBFs with X-braces, the members under tension should only be taken into account, whereas for (Chevron) V-braces both tensile and buckling members should be considered. In general, for structures where the number of storeys is larger than two, the normalised slenderness $(\bar{\lambda})$ should satisfy the limits provided below: 


$$
1.3<\bar{\lambda}=\sqrt{\frac{A f_{y}}{N_{c r}}}<2
$$

$A$ is the cross-sectional area of the brace, $f_{y}$ the yield stress and $N_{c r}$ the critical buckling load. It should also be noted that both diagonals on a V-brace should be able to resist any seismicunrelated loads. This check should be performed by comparing the action $\left(N_{E d}\right)$ against the member plastic resistance $\left(N_{p l, R d}\right)$ for the tensile brace, and the post-buckling resistance $\left(\gamma_{R b} N_{b, R d}, \gamma_{R b}=0.3\right)$ for the brace under compression.

Table 2: Brace design checks

\begin{tabular}{ccccccc}
\hline & \# storey & Section & $\Lambda$ & $N_{p l}(\mathrm{kN})$ & $N_{E d}(\mathrm{kN})$ & $\Omega$ \\
\hline \multirow{6}{*}{ 6-storey } & 1 & SHS150x16.0 & 1.35 & 3044.48 & 2725.16 & 1.12 \\
CBF & 2 & SHS150x16.0 & 1.35 & 3044.48 & 2457.75 & 1.24 \\
& 3 & SHS140x14.2 & 1.44 & 2536.63 & 1942.31 & 1.31 \\
& 5 & SHS140x14.2 & 1.44 & 2536.63 & 1854.64 & 1.37 \\
& 6 & SHS140x8.0 & 1.38 & 1499.52 & 1160.82 & 1.29 \\
& SHS140x7.1 & 1.37 & 1339.90 & 965.51 & 1.39 \\
\hline
\end{tabular}

Table 3: Column design checks

\begin{tabular}{ccccccccc}
\hline & \# storey & Section & $\chi$ & $N_{p l}(\mathrm{kN})$ & $\begin{array}{c}N_{E d(G+0.3 Q)}(\mathrm{kN}) \\
1.1 \times 1.25 \times \Omega \times N_{E d} \\
(\mathrm{kN})\end{array}$ & $\begin{array}{c}N_{\text {tot }} \\
(\mathrm{kN})\end{array}$ & $\chi N_{p l} / N_{\text {tot }}$ \\
\hline & 1 & HEM550 & 0.86 & 12567.00 & 1427.99 & 7768.14 & 9196.13 & 1.18 \\
6-storey & 2 & HEM550 & 0.86 & 12567.00 & 1238.15 & 7664.19 & 8902.33 & 1.21 \\
CBF & 4 & HEB500 & 0.85 & 8484.50 & 915.96 & 3827.35 & 4743.31 & 1.53 \\
& 5 & HEB500 & 0.85 & 8484.50 & 729.43 & 3696.49 & 4425.92 & 1.64 \\
& 5 & HEA450 & 0.85 & 6319.00 & 423.41 & 917.54 & 1340.95 & 4.02 \\
\hline
\end{tabular}

Table 4: Beam design checks

\begin{tabular}{ccccccc}
\hline & \# storey & Section & $\begin{array}{c}1.1 \times 1.25 \times \Omega \times N_{E d} \\
(\mathrm{kN})\end{array}$ & $\begin{array}{c}M_{E d(G+0.3 Q)} \\
(\mathrm{kNm})\end{array}$ & $\begin{array}{c}M_{N, R d} \\
(\mathrm{kNm})\end{array}$ & Check \\
\hline \multirow{2}{*}{ 6-storey } & 2 & HEB450 & 3679.41 & 226.92 & 864.45 & 1.32 \\
CBF & 4 & HEA450 & 2624.66 & 227.20 & 781.64 & 1.37 \\
& 6 & HEA360 & 1266.36 & 193.48 & 640.90 & 1.58 \\
\hline
\end{tabular}

\section{Step 3: Nonlinear Model}

Modelling-wise, all braces are taken into account, regardless of tensile or compressive actions. Brace-frame as well as beam-column connections are considered pinned, while columns themselves are assumed fixed to the ground due to the effect that the rather stiff brace-frame flanges are expected to have locally, despite the initial design-basis assumption for pinned support conditions (Figure 3). Gravity loads (Table 1) are introduced to the model through a leaning column that carries only $50 \%$ of the vertical loads acting on the structure due to plan-view symmetry. The cross-braces are modelled using a physics-based approach $[14,15]$, by applying an initial imperfection equal to $L / 250$ ( $L=$ the element length) on the midpoint of each member representing a brace. The effective length of the brace is determined by considering (numerically) rigid elements to take the effect of gusset plates into account, eventually reducing the effective brace length down to $70 \%$ of the actual. 

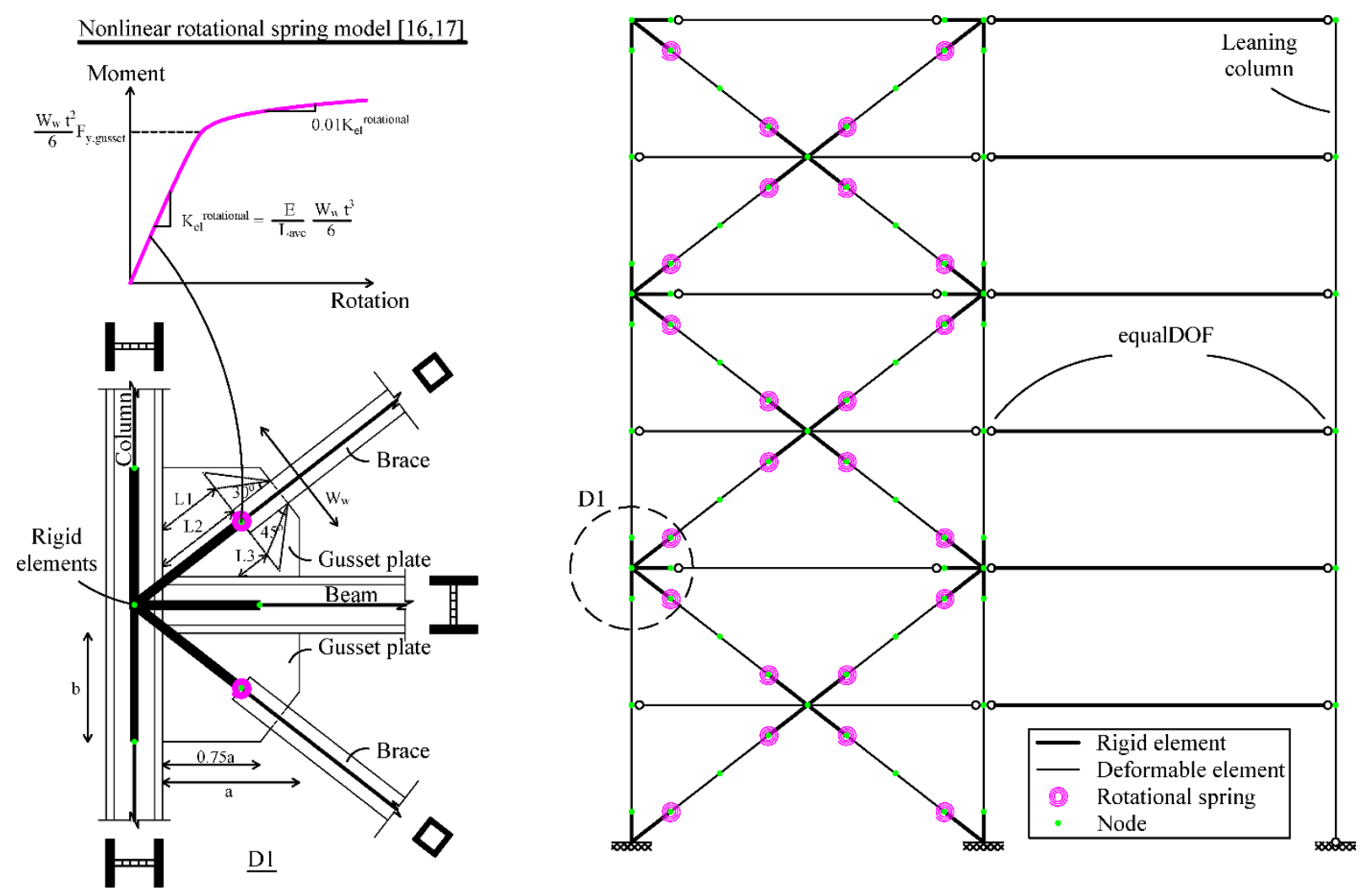

Figure 3: Structural model considered

Nonlinear force-based beam-column fibre elements are adopted to model braces, beams and columns on the CBFs, while elastic beam-column elements are used for the leaning column and the rigid elements. Diaphragm rigidity representing the concrete slab is taken into account through an equivalent rigid truss element that is assigned a rather large stiffness value. Convergence issues stemming from buckling braces are resolved using (additional) corotational truss elements of marginal stiffness. P- $\Delta$ geometric transformation is considered for all beams and columns (leaning column included), while the corotational transformation is preferred for the braces as it is suitable for large-displacement-small-strain problems. As far as the modelling of the brace-frame connections is concerned, a typical $40 \mathrm{~mm}$ thick steel gusset plate is considered. The effect of the aforementioned plate, adopted both for the brace-column and the brace-beam connections, is taken into account though a nonlinear zero-length rotational spring, the properties of which are estimated based on the relationships proposed by Hsiao et al. [16,17] as shown in Figure 3. The Steel02 material [18] from the OpenSees [19] library is adopted, using a steel Young's modulus $E=210 \mathrm{GPa}$, the expected yield strength $f_{y}=1.2 \cdot 355=426 \mathrm{MPa}$, a post-yield hardening ratio $\alpha_{h}=0.3 \%$ and parameters that control the transition from elastic to plastic branches, i.e. $R_{0}=20, c_{R 1}=0.925$ and $c_{R 2}=0.15$. The hysteretic-behaviour parameters $a_{1}=0.0005$, $a_{2}=0.01, a_{3}=0.0005$ and $a_{4}=0.01$ are taken into account according to the Uriz and Mahin [15] approach. On top of Steel02, the OpenSees fatigue material [19] is also considered for the braces, in order to account for any potential fatigue-related failure due to cyclic loading.

Modal analysis is initially performed for both case studies to determine the fundamental periods of vibration $\left(T_{1}\right)$ as well the associated mass participation ratios. Although this task is trivial compared to the nonlinear analysis presented later in this section, it is necessary not only because it provides information (e.g. $T_{1}$ ) that will be exploited during the post-processing of the nonlinear-analysis results, but also due to the verification of the OpenSees model against the 
ETABS model that has been used during the design of the case study. According to Table 5, discrepancies are evident among the two approaches. In general, the OpenSees model is stiffer due to rigid-links that reduce the element length, as well as the non-pinned hinges in place of the pinned ones employed in ETABS, as per standard engineering practice.

Table 5: Modal analysis results; OpenSees versus ETABS

\begin{tabular}{ccccc}
\hline & \multicolumn{2}{c}{ OpenSees } & \multicolumn{2}{c}{ ETABS } \\
\hline Number of & Fundamental period & Mass participation & Fundamental period & Mass participation \\
storeys & $T_{1}(\mathrm{~s})$ & ratio $(\%)$ & $T_{1}(\mathrm{~s})$ & ratio $(\%)$ \\
\hline 6 & 1.15 & 75.00 & 1.65 & 79.43 \\
\hline
\end{tabular}

\section{Step 4: Static Analysis}

Consequently, nonlinear static analysis is executed in order to obtain a first guess regarding the actual behaviour factor of the case studies under investigation. A multilinear fit is performed on each pushover curve to derive the approximate (first) yield point $\left(\theta_{\max , y}, V_{b, y}\right)$, the peak response $\left(\theta_{\text {max,peak }}, V_{b, p e a k}\right)$ and the ultimate capacity point $\left(\theta_{\max , u}, V_{b, u}\right)$ that corresponds to a $20 \%$ drop of the system's strength (i.e. $V_{b, u}=0.8 V_{b, p e a k}$ ). The behaviour factor using nonlinear static analysis may then be estimated as $q_{\text {stat }}=q_{d} \cdot \Omega=\theta_{\max , u} / \theta_{\max , y} \cdot V_{b, p e a k} / V_{b, y}$. Extracting the associated values from Figure 4 provides the behaviour factor for the 6 -storey $\mathrm{X}-q_{\text {stat, } 6} \approx 10.8$. At this point, the behaviour factor for our case study is deemed acceptable and the verification process may advance to the $q$-factor evaluation using dynamic analysis results. It should also be noted that ideally a redesign should be performed in order to derive the optimal $q$-factor, as the comparison of $q_{\text {stat }, 6}$ against the design $q$-factor deviates by a fraction greater than $20 \%$.

Two additional (capacity) points are depicted on the pushover curve, namely the " $1{ }^{\text {st }}$ element to yield" and " 1 st element to exceed the Significant Damage (SD) capacity". Although the former is quite simple to capture by looking for the axial strain that exceeds the associate yield $\left(\varepsilon_{y}\right)$ on an element basis, the latter is triggered upon the exceedance of an axial strain value $\left(\varepsilon_{S D}\right)$ that equals $75 \%$ of the ultimate/fracture strain $\left(\varepsilon_{u}\right)$, and will further be adopted for the assessment of the behaviour factor using nonlinear dynamic analysis.

$$
\varepsilon_{S D}=0.75 \varepsilon_{u}
$$

Ideally $\varepsilon_{u}$ should be estimated via a series of experimental tests; alternatively, via direct model measurements on each element of interest (i.e. braces), or even through analytical equations for simplicity. For the purpose of this study, $\varepsilon_{u}$ is estimated using the equation proposed by Hsiao et al. [17] for the maximum strain-range $\left(\varepsilon_{\text {range }}\right)$.

$$
\max \left(\varepsilon_{\text {range }}\right)=0.1435\left(\frac{w}{t}\right)^{-0.4}\left(\frac{k L}{r}\right)^{-0.3}\left(\frac{E}{f_{y}}\right)^{0.2}
$$

$\varepsilon_{\text {range }}$ is the sum of the absolute compressive and tensile strains for every step of the loading history, $w / t$ refers to the class, $k L / r$ to the slenderness and $E / f_{y}$ to the (expected) steel grade of the brace section. During an earthquake, the brace is subjected to strain values considerably smaller than $\varepsilon_{\text {range }}$, and thus $\varepsilon_{u}$ is assumed to be approximately equal to $50 \%$ of the maximum Erange.

$$
\varepsilon_{u}=\frac{\max \left(\varepsilon_{\text {range }}\right)}{2}
$$


Strain $(\varepsilon)$ values may be translated into (roof, storey or maximum inter-storey) drift $(\theta)$ estimates as:

$$
\theta=\frac{\varepsilon L_{\text {brace }}}{H_{\text {storey }} \cos \phi}
$$

$L_{\text {brace }}$ is the brace length, $H_{\text {storey }}$ the storey height and $\varphi$ the angle defined by the brace and the horizontal. According to Figure 4, the simplified solution of Eq. (6) provides similar results to the strain-based approach for each element regarding the $1^{\text {st }}$ yield, which by the way appears following the onset of buckling on the $1^{\text {st }}$ brace. Table 6 summarises the 'Significant Damage' and 'Global Collapse' (GC) limit states in terms of strain and maximum inter-storey drift.

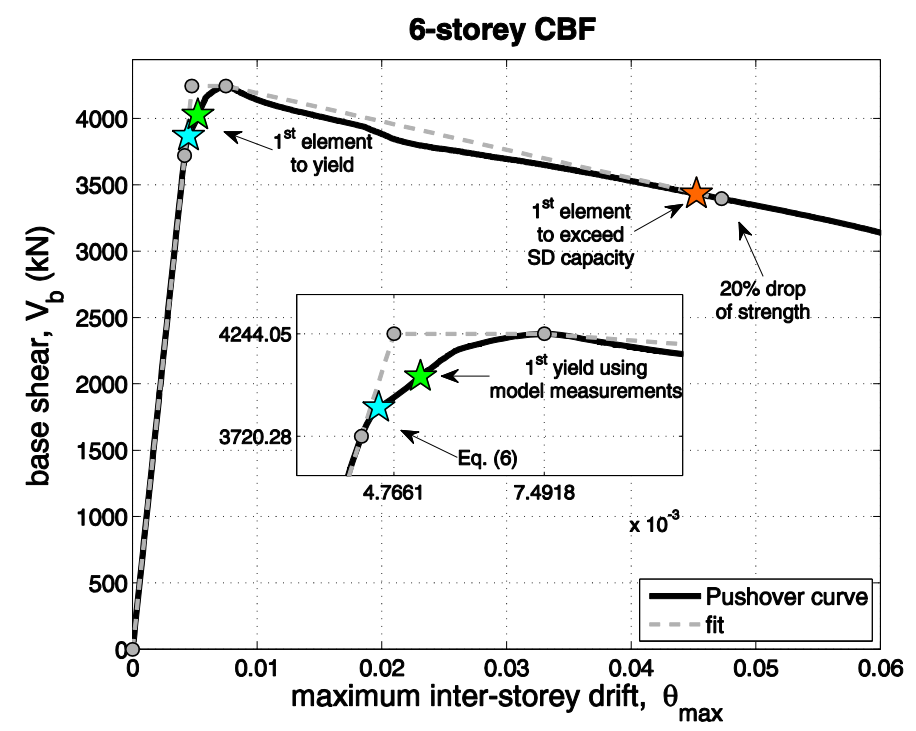

Figure 4: 6-storey CBF Nonlinear Static Analysis

Table 6: Limit state capacities in terms of strain and maximum inter-storey drift

\begin{tabular}{cccc} 
& Limit State & $\varepsilon(\%)$ & $\theta_{\max }(\%)$ \\
\hline \multirow{2}{*}{ 6-storey } & SD & 2.27 & 4.69 \\
& GC & 3.03 & 6.25 \\
\hline
\end{tabular}

\section{Step 5: Dynamic Analysis}

IDA is subsequently performed to derive a refined representation of the space that is defined among engineering demand parameters $(E D P S)$ of interest and ground motion intensity measures, that will eventually be exploited for the robust assessment of the behaviour factor. For the purpose of this study, the maximum inter-storey drift ratio (i.e. $\theta_{\max }$ ) is adopted as the $E D P$ and the average spectral acceleration shown in Eq. (1) as a state-of-the-art IM. The IDA output for the high-seismicity record set (Step 1) is presented in Figure 5(a). Having such vast information on the structural response at our disposal enables the accurate probability of exceedance estimation for any of the limiting criteria defined above (Table 6). The estimation may simply be performed by considering a vertical cut (or EDP stripe) of the IDA plane on each $E D P$ capacity of interest (e.g. SD, GC). Interpolating the single-record IDA curves with each $\theta_{\max }$ capacity results in vertical stripes of the so-called $I M$-capacities, or in other words the values that define the damage state distribution. Such information is conveniently summarised using the well-known fragility curves presented in Figure 5(b). Therein, the probability that 
demand $(D)$ violates the aforementioned limit states capacities $(C)$ is provided for several values of seismic intensity.

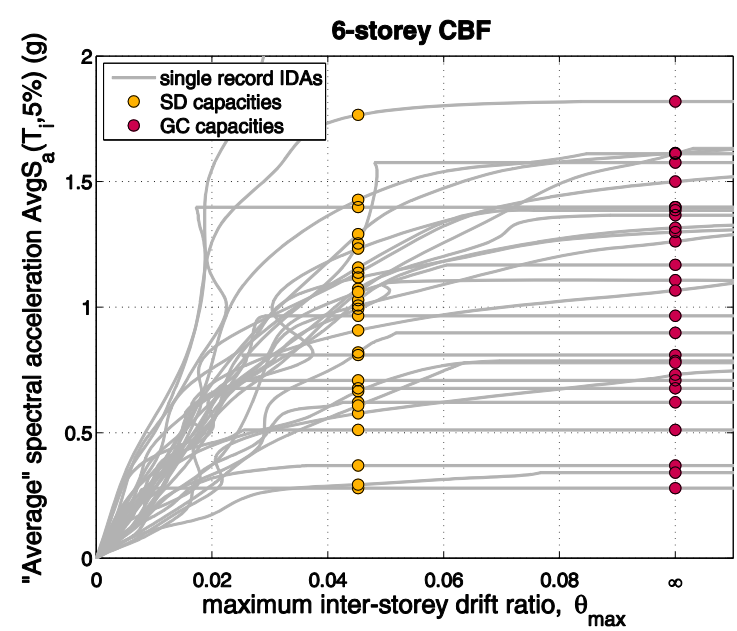

(a)

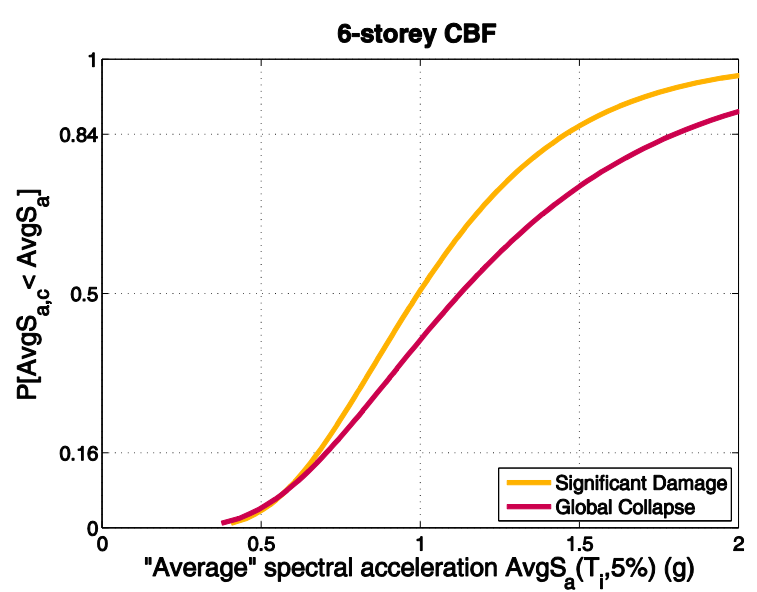

(b)

Figure 5: (a) Single record IDAs along with the associated SD and GC capacities and (b) fragility curves

\section{Step 6: Performance assessment}

The risk-based assessment is performed according to the Cornell et al. [20] fragility-hazard convolution approach (Figure 6) to determine $\lambda_{D S}$, i.e., the mean annual frequency (MAF) of exceeding the damage state ( $D S$, being either SD or GC) of interest:

$$
\lambda_{D S}=\int_{I M} \mathrm{P}[D>C \mid I M]|\mathrm{d} \lambda(I M)|
$$

In our case, the seismic fragility output of Figure 5(b) is combined with the Istanbul $A v g S_{a}$ seismic hazard curve (Step 1) in order to provide the mean annual frequency of exceedance for the limit state capacities under investigation, as shown in Figure 6.
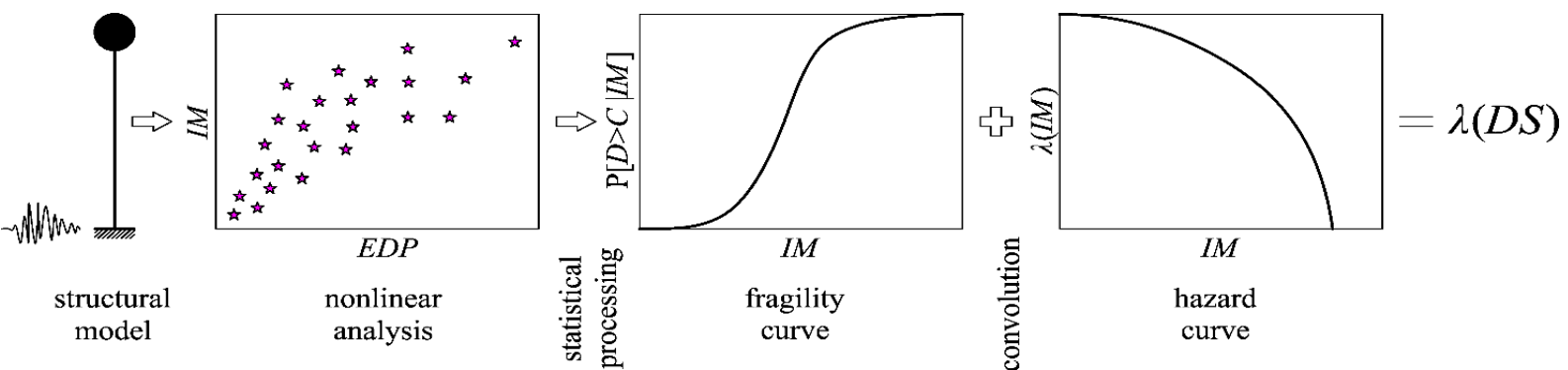

Figure 6: The concept of performance assessment for a given damage state $(D S)$, by extracting the fragility curve from nonlinear dynamic analyses and convolving with the hazard curve over all values of the IM.

\section{Step 7: Acceptance or rejection of q-factor}

The case study MAFs, the associated limiting values $\left(\lambda_{\text {lim }}\right)$, the margin ratio $\left(\lambda_{\text {lim }} / \lambda\right)$ and the allowable margin ratio are summarised in Table 7 for both SD and GC. The latter may be estimated as

$$
A M R=e^{k \cdot k_{x} \cdot \beta_{u}}
$$


where $\beta_{u}$ is the epistemic uncertainty dispersion, $k_{x}$ the inverse of the standard normal cumulative distribution function of a value $x \in[0,1]$ representing the confidence (i.e. the percentage of buildings that satisfy the limit state check), and $k$ the hazard slope. As an example, $k_{x}$ was assumed to be equal to $1.0, \beta_{u}$ equal to 0.3 , while $k$ was estimated equal to 2.83 and 3.89 for the $\mathrm{SD}$ and GC limit states, respectively.

Table 7: Behaviour factor verification via the limit state mean annual frequency estimation

\begin{tabular}{cccccc} 
& Limit State & $\lambda(\%)$ & $\lambda_{\text {lim }}(\%)$ & Margin Ratio $\left(\lambda_{\text {lim }} / \lambda\right)$ & Allowable Margin Ratio \\
\hline \multirow{2}{*}{ 6-storey } & SD & 0.0549 & 2.1 & 38.37 & 2.34 \\
& GC & 0.0602 & 0.2 & 3.34 & 3.21 \\
\hline
\end{tabular}

Comparing the margin ratio against its allowable value determines the acceptance or rejection of the design-basis $q$-factor. In our case, both limit state MAFs are well-below the relevant MAF limits, which implies that the initial (design) assumption for a behaviour factor $q=4$ is acceptable.

\section{CONCLUSIONS}

The methodology presented comprises a unique tool for the risk-based assessment of the design behaviour factor. It combines the fundamental concepts of performance-based earthquake engineering with state-of-the-art tools such as Conditional Spectrum record selection, IDA and AvgSa. Although it is targeted to novel structural systems that are not part of recent codes and standards, its application does not meet any particular constraints, and as a result it may also be used to verify the behaviour factors that are currently used in practice for conventional lateral load-bearing configurations. Limitations and potential improvements on the procedure have already been discussed [3]; therefore, the authors wish to focus on the actual application and highlight the importance of the rigorous estimation of limit state capacities and the associated dispersions, that are expected to have a major impact on the final output of this well-established step-by-step procedure.

\section{REFERENCES}

[1] CEN. "Eurocode 8 : Design of structures for earthquake resistance - Part 1: General rules, seismic actions and rules for buildings (EN 1998-1:2004)." European Standard NF EN. CEN, Brussels, 2004.

[2] FEMA. "Quantification of Building Seismic Performance Factors." FEMA P-695, prepared by Applied Technology Council for Federal Emergency Management Agency, Washington, D.C., 2009.

[3] Vamvatsikos D, Castiglioni C, Bakalis K, Calado L, D'Aniello M, Degee H, et al. “A risk-consistent approach to determine behavior factors for innovative steel lateral load resisting systems." Proceedings of the 8th European Conference on Steel and Composite Structures, Copenhagen, Denmark, 2017.

[4] Vamvatsikos D and Cornell CA. "Incremental dynamic analysis." Earthquake Engineering \& Structural Dynamics [Internet], Vol. 31, No.3, 2002 [cited 2014 Mar 27], pp. 491-514. Available from: http://doi.wiley.com/10.1002/eqe.141

[5] Kohrangi M, Bazzurro P and Vamvatsikos D. "Vector and Scalar IMs in Structural Response Estimation: Part II - Building Demand Assessment." Earthquake Spectra, Vol. 53, No.9, 2016, . 
[6] Kazantzi AK and Vamvatsikos D. "Intensity measure selection for vulnerability studies of building classes." Earthquake Engineering \& Structural Dynamics [Internet], Vol. 44, No.15, 2015, pp. 2677-94. Available from: http://doi.wiley.com/10.1002/eqe.2603

[7] Giardini D, Woessner J, Danciu L, Crowley H, Cotton F, Grünthal G, et al. "Seismic Hazard Harmonization in Europe (SHARE): Online Data Resource.” 2013.

[8] Lin T, Haselton CB and Baker JW. "Conditional spectrum-based ground motion selection. Part I: Hazard consistency for risk-based assessments." Earthquake Engineering \& Structural Dynamics [Internet], Vol. 42, No.12, 2013, pp. 1847-65. Available from: http://doi.wiley.com/10.1002/eqe.2301

[9] Lin T, Haselton CB and Baker JW. "Conditional spectrum-based ground motion selection. Part II: Intensity-based assessments and evaluation of alternative target spectra." Earthquake Engineering \& Structural Dynamics [Internet], Vol. 42, No.12, 2013, pp. 1867-84. Available from: http://doi.wiley.com/10.1002/eqe.2303

[10] Cordova P, Deierlein G, Mehanny SF and Cornell CA. "Development of a two-parameter seismic intensity measure and probabilistic design procedure." The Second US- Japan Workshop on Performance-Based Earthquake Engineering Methodology for Reinforced Concrete Building Structures, Sapporo, Hokkaido, p. 187-206.

[11] Vamvatsikos D and Cornell CA. "Developing efficient scalar and vector intensity measures for IDA capacity estimation by incorporating elastic spectral shape information." Earthquake Engineering and Structural Dynamics, Vol. 34, No.13, 2005, pp. 1573-600.

[12] Kohrangi M, Bazzurro P, Vamvatsikos D and Spillatura A. "Conditional spectrum-based ground motion record selection using average spectral acceleration." Earthquake Engineering \& Structural Dynamics [Internet], Vol. 44, 2017, pp. 657-75. Available from: http://doi.wiley.com/10.1002/eqe.2876

[13] Kohrangi M, Vamvatsikos D and Bazzurro P. "Site dependence and record selection schemes for building fragility and regional loss assessment." Earthquake Engineering \& Structural Dynamics [Internet], No.i, 2017, . Available from: http://doi.wiley.com/10.1002/eqe.2873

[14] Uriz P, Filippou FC and Mahin SA. "Model for Cyclic Inelastic Buckling of Steel Braces." Journal of Structural Engineering [Internet], Vol. 134, No.4, 2008, pp. 619-28. Available from: http://ascelibrary.org/doi/10.1061/\%28ASCE\%2907339445\%282008\%29134\%3A4\%28619\%29

[15] Uriz P and Mahin S a. "Toward Earthquake-Resistant Design of Concentrically Braced Steel-Frame Structures.” PEER Report No. 2008/08, Pacific Earthquake Engineering Research Center, University of California, Berkeley, CA, 2008.

[16] Hsiao P-C, Lehman DE and Roeder CW. "Improved analytical model for special concentrically braced frames." Journal of Constructional Steel Research [Internet], Elsevier Ltd, Vol. 73, No.2012, 2012, pp. 80-94. Available from: http://dx.doi.org/10.1016/j.jcsr.2012.01.010

[17] Hsiao P-C, Lehman DE and Roeder CW. "A model to simulate special concentrically braced frames beyond brace fracture." Earthquake Engineering \& Structural Dynamics [Internet], Vol. 42, No.2, 2013, pp. 183-200. Available from: http://doi.wiley.com/10.1002/eqe.2202

[18] Menegotto M and Pinto PE. "Method of analysis for cyclically loaded R .C. plane frames including changes in geometry and non-elastic behaviour of elements under combined normal force and bending." Preliminary Report IABSE, vol 13, 1973.

[19] McKenna F and Fenves GL. "The OpenSees Command Language Manual (1.2 edn)." 2001. 
[20] Cornell CA, Jalayer F, Hamburger RO and Foutch D. "Probabilistic Basis for 2000 SAC Federal Emergency Management Agency Steel Moment Frame Guidelines.” Journal of Structural Engineering. 2002. p. 526-33. 